\title{
¿Crítica desde la derecha o desde la izquierda? Respuesta a Ernst Bloch $^{1}$
}

Francisco García Chicote

Universidad de Buenos Aires, Buenos Aires, Argentina. Doctor en Letras Modernas, Jefe de Trabajos Prácticos de Literatura Alemana.

fgchicote@gmail.com

Recebido em: 27/11/2018

Aceito para publicação em: 29/11/2018

\footnotetext{
${ }^{1}$ El presente artículo, escrito en 1943, fue publicado recién en 1984 por Miklós Mesterházi y Gyórgy Mezei (MESTERHÁZI y MEZEI, 1984). Károly Urbán, historiador del Partido Comunista, encontró el texto en el Archivo Central del Partido del Instituto de Marxismo-Leninismo del Comité Central del SED (Partido Socialista Unificado de Alemania, por sus siglas en alemán), en la República Democrática Alemana. Lukács responde aquí al breve ensayo de Bloch "Der Nazi kocht im eigenen Saft" (El nazi se cocina en su propia salsa), que apareció en el periódico de la emigración alemana en México, Freies Deutschland (Alemania libre, abril de 1942, $\mathrm{n}^{\mathrm{o}}$ 6). Traducción de Francisco García Chicote (Universidad de Buenos Aires). Todas las notas son del traductor al español, quien se ha basado en la edición, las notas y la introducción de Miklós Mesterházi (MESTERHÁZI y MEZEI, 1984), a quien desea agradecer por la demás ayuda prestada. Entre corchetes angulares (“<>”) se consignan tachaduras, y entre "/: : " se señalan agregados. Entre corchetes (“[]”) se incluyen términos del original alemán.
} 


\section{Resumen}

Traducción del artículo ¿Crítica desde la derecha o desde la izquierda? Respuesta a Ernst Bloch, de Georg Lukács

Palabras-clave: Traducción del artículo. Georg Lukács

\section{Abstract}

Translation of the article Critical from the right or from the left? Reply to Ernst Bloch, by Georg Lukács

Keywords: Translation of the article. Georg Lukács 
Mi querido Ernst:

Ya han pasado más de treinta años desde aquella tarde, para mí inolvidable, en la que tuvimos nuestra primera conversación nocturna en diferentes cafés de Budapest y en las calles. Desde entonces, esta conversación fue retomada una y otra vez, en Florencia y Ravena, en Heidelberg, en Berlín y en Viena. 57 Siempre trató de cuestiones importantes. Siempre se mantuvo un cierto tono básico en estas conversaciones, si bien ambos, y con nosotros nuestras conversaciones, estuvimos sujetos a un gran cambio: casi siempre hubo entre nosotros un consenso respecto de la última meta, sin embargo, hubo igualmente casi siempre una divergencia, en ocasiones aguda, en los métodos. Pero creo que precisamente esta divergencia hizo que este diálogo fuese interesante y fructífero.

También hoy me compele tu ensayo ${ }^{58}$ a una réplica que tiene, <en mi opinión>, como yo creo, igualmente el carácter de nuestras viejas conversaciones. Se trata nuevamente de cuestiones centrales: planteás el problema de la ideología fascista en su relación con el desarrollo alemán y formulás al respecto - muy correctamente - la pregunta: si Hitler cae, ¿entonces qué? La pregunta es /: más que:/ importante. Y el viejo fundamento del diálogo, nuestro consenso respecto de la última meta, el hecho de que el hitlerismo y todo lo diabólico que él ha fraguado deben ser erradicados, también está presente hoy. Pero también lo está el otro aspecto, nuestra divergencia respecto de los métodos, y por ello tomo la palabra, si bien lamentablemente en un alejamiento de muchos miles de kilómetros, 59 para que también en esta cuestión tenga lugar entre nosotros un posible acuerdo o, por lo menos, una clarificación de las visiones.

¿En qué punto nos separamos el uno del otro? Creo que el punto central de la divergencia reside en el hecho de que vos considerás a Hitler de manera aislada con relación al desarrollo alemán. ¿Qué resulta de esto? En primer lugar, la toma del poder de Hitler, los diez años de su dominio, la tenacidad de su resistencia contemporánea, permanecen como un enigma. En segundo término, si los nazis, como vos decís, se cocinaran realmente únicamente en su propia salsa, el señor Hitler sería realmente lo que él solamente se figura ser y lo que él deja anunciar sobre sí, es decir, un genio. Pues si lograse llegar al poder sin un desarrollo precedente, que ha acarreado en el pueblo alemán una desmoralización social y moral tal que este haya podido también dejarse estafar por

\footnotetext{
${ }^{57}$ Lukács y Bloch se conocieron en Berlín durante el semestre de invierno de 1909-1910 a través de Georg Simmel. En 1912, Bloch visita Budapest y pasa luego la primavera con Lukács en Florencia y Ravenna. Durante esa estadía, convence a Lukács a ir juntos a Heidelberg, donde mantienen diversos vínculos con el círculo de Max Weber. Vuelven a encontrarse, luego de varios años de separación, en 1921 en Berlín, y luego, algunos años más tarde, en Viena. Sobre la relación personal entre Lukács y Bloch, véase Mesterházi (1984), Bloch (1984) y Zudeick (1992). La edición más completa del intercambio epistolar entre los dos amigos es de Mesterházi y Mezei (1984).

${ }^{58}$ Se refiere a "Der Nazi kocht im eigenen Saft" (El nazi se cocina en su propia salsa); ver nota 2.

${ }^{59}$ Lukács escribe desde Moscú; Bloch pasa su exilio en Nueva York.
} 
Francisco García Chicote | ¿Crítica desde la derecha o desde la izquierda? Respuesta a Ernst Bloch

un tal granuja; si hubiese realizado todo esto realmente a partir de su propia fuerza, sería realmente un genio. Vos querés, correctamente, desenmascararlo como un granuja talentoso, pero tu argumentación es más una exaltación que un desenmascaramiento. En tercera y última instancia, la pregunta “¿qué viene después de Hitler?” Decís que los antifascistas que investigan la prehistoria del fascismo "proveen sin quererlo y sin saberlo ciertos medios a la reacción para desvalorizar a tiempo también lo venidero que después de Hitler pueda venir desde Alemania". Creo, por el contrario, que precisamente el aislamiento de Hitler respecto de las líneas de desarrollo políticas e ideológicas pasadas de la reacción en Alemania facilita y no complica una reorganización de las fuerzas reaccionarias dentro y fuera de Alemania.

Estas serían hoy pues nuestras diferencias de opinión. ¿Dónde yace la base? Me parece que en el hecho de que tu formulación de preguntas es demasiado abstracta. Hablás de que el fascismo es una manifestación internacional y decís más adelante que "sus raíces yacen en la economía, no en las cavilaciones [Bedenklichkeiten] del alma alemana". Lo primero considero totalmente correcto. Pero no revela sobre nuestro problema absolutamente nada. Puede haber un fascismo alemán, italiano, finés etc.; podemos constatar en el plano teórico esta internacionalidad con la conciencia tranquila. Sin embargo, esto no dispensa a los antifascistas alemanes de la obligación de destruir la ideología del fascismo alemán con armas alemanas, del mismo modo que los italianos etc. están obligados a hacer esto sobre su propio terreno con sus propias armas. Solo en la medida en que cada uno cumpla con este deber /: suyo inmediato y encomendado por la historia:/ <sobre su propio terreno, con sus propias armas> - por cierto en una coordinación lo más internacionalmente posible de la lucha -, se puede combatir de manera concreta en el plano internacional una manifestación internacional como el fascismo. Ya el viejo demócrata Freiligrath vio claramente esta cuestión: “iPoné orden en tu propia casa! ¡Poné orden y / resistí! Para cazar a Jellachich, jarroja tu / Jellachich!”60

Considero la segunda frase correcta, a excepción del contraste. Pero tené en mente que la estructura económica, desde un punto de vista abstracto, es en los países capitalistas más desarrollados en su mayor parte similar... ¿por qué hay aquí fascismo y allí no? Decís que este está "por todos lados en la sociedad actual latente". Eso puede ser correcto, y escritores americanos significativos como Jack London y Sinclair Lewis han escrito críticas sociales interesantes al pensar hasta el final esta latencia. Pero precisamente vos sabrás mejor cuán profundo es el abismo que separa lo <latente>

\footnotetext{
${ }^{60}$ Se trata de versos del poema "Wien" (Viena), aparecido en 1949 en la Neue Rheinische Zeitung (Nueva gaceta renana), el órgano revolucionario publicado por Karl Marx y Friedrich Engels entre 1848 y 1849. El poeta Ferdinand Freiligrath (1810-1876) participó activamente en los movimientos revolucionarios en Europa Central de 1848-9. Las líneas remiten al conde Josip Jelačić von Bužim, que jugó un papel destacado en los movimientos contrarrevolucionarios del período.
} 
meramente posible de lo realizado. ${ }^{61}$ No es empero ninguna casualidad que el pueblo alemán haya soportado diez años de hitlerismo, mientras que en Francia ninguna opresión, ningún dominio de Petain o Laval, ninguna demagogia de De La Roque o de Doriot pudo acarrear un movimiento fascista digno de nombrar.

Por cierto, /:las:/ "cavilaciones del alma popular" <es $>$ no ofrecen tampoco ninguna solución. El alma popular, para conservar la expresión, no es ninguna cosa en sí suprahistórica, sino más bien el destino < histórico $>$ que se transforma históricamente de un pueblo. La concreta estructura socio-política surgida históricamente de este modo, la forma concreta de la economía, de la estructura político-social, de las tradiciones [Überlieferungen] ideológicas: de todas estas formas depende si el fascismo es un peligro latente o se torna en una realidad terrible, y con ello parte y factor del desarrollo histórico, del histórico destino popular. Ahora bien, de esto se sigue que la superación del fascismo es igualmente una parte, un factor de este destino. De esto se sigue, además, que la discusión acerca del camino histórico que condujo al fascismo conforma igualmente un factor integral de su real superación.

De esta manera llegamos al punto decisivo de nuestra discusión, a la cuestión del método. Me parece que aquí debe tratarse de una crítica realmente concreta. <Esta es justamente realmente independiente de> Tenés razón: <él> los nazis de hecho han intentado apropiarse de lo más variado. 62 Pero de eso no se sigue que, en nuestra crítica, deberíamos permanecer en esta aleatoriedad. Más bien deberíamos constatar que <él> adoptaron muchos elementos radicalmente reaccionaros y los desarrollaron de manera aún más reaccionaria; otras cosas, que conforme a su esencia eran progresivas, las ensuciaron y falsificaron. Nuestra tarea es el restablecimiento de la verdad y la realidad históricas. Debemos diferenciar agudamente entre Gentz o Lagarde por un lado y entre

\footnotetext{
${ }^{61}$ Referencia al concepto de latencia, que recorre toda la obra de Bloch. Mesterházi escribe al respecto: "El verdadero pathos de la filosofía blochiana parte de la idea de que en todo ser humano existe una pulsión utópica, una anticipación del estado de libertad, en la que las cosas no tienen ya una existencia independiente del objeto, en la que las barreras entre sujeto y objeto no pueden ya tener lugar. El ansia en el ser humano, su necesidad utópica produciría un excedente de subjetividad con respecto a su estado respectivo, un excedente que se realiza en sueños, ideologías, y en el arte, que consecuentemente no puede ser concebido desde el punto de vista de la sociología vulgar. El ansia de la subjetividad a la realización sería al mismo tiempo el descubrimiento de la voluntad del objeto, la libertad humana al mismo tiempo la realización del sentido de la naturaleza” (MESTERHÁZI, 1984, p. XXII).

${ }^{62}$ Se lee en el ensayo de Bloch: "En la composición de la mentira, el nazi es original, pero toma el material donde lo encuentra. Lo toma del superhombre y del terruño, del socialismo y de la raza superior nórdica, del Anillo de los Nibelungos y de la Flauta Mágica (Goebbels la llamó "la excelsa canción de la humanidad alemana"), del antisemitismo y al Señor del Seboat, el Dios del Antiguo Testamento. En la cultura alemana, en las manifestaciones problemáticas de la cultura alemana, pero finalmente en toda la historia humana hay premisas de este tipo para el nazismo, es decir las premisas que se agarra un tunante para hacer mierda del oro o, en el peor de los casos, del oropel. Pero es un completo sinsentido dejarse timar por los nazis sobre un legado cultural alemán. O usar al nazi también solamente como medio de prueba y juicio de formaciones problemáticamente significativas del pasado. Para ello el marxista tiene a disposición otros medios, tales que no consisten en aceptaciones opacas de premisas y no le arrebatan a Hitler Wagner de las manos. De modo que Hitler finalmente se yerga gigantesco, flanqueado por un músico alemán, por un filósofo alemán" (BLOCH, 1984, p. 276).
} 
Francisco García Chicote | ¿Crítica desde la derecha o desde la izquierda? Respuesta a Ernst Bloch

Thomas Münzer o Hörderlin por el otro.63 /:Independientemente de lo que los fascistas afirmen sobre ellos.:/

Pero esta concreción, esta completa independencia intelectual respecto no solo de las valoraciones de los mismos nazis, sino también de la precedente ideología de la fascistización tiene una determinación ideológico-política muy correcta: toda crítica tiene una dirección. Toma partido, por lo menos en el gran sentido histórico, si bien no necesariamente en consonancia con ningún partido organizado. Esta dirección es crucial para el carácter y para los resultados de la crítica. Desde un punto de vista abstracto, siempre hay solamente un sí o un no, una aceptación o un rechazo. Desde el punto de vista concreto es esencialmente otra cosa. Se pregunta: ¿de dónde proviene una aceptación o un rechazo? ¿Desde la derecha o desde la izquierda?

Aquí estaría por lo tanto nuestra diferencia metodológica. En tu ensayo, no hacés esta diferencia. Por ejemplo, decís sobre Nietzsche que "hasta el hastío debe hacerse notar que Nietzsche era un enemigo del Reich de Bismarck". Recordarás de nuestras viejas conversaciones una de mis citas preferidas. Mi fallecido amigo de juventud, Leo Popper, solía decir: Es imposible convertir faltas gramaticales en peculiaridades de estilo mediante la repetición obstinada. Igualmente sucede con la cuestión Nietzsche-Bismarck. Visto de manera abstracta, es verdad que Nietzsche criticó ininterrumpidamente a Bismarck. Pero debe plantearse la pregunta: ¿Por qué lo criticó? ¿De dónde proviene esta crítica y hacia dónde va?

Nietzsche se ha expresado clara y sinceramente al respecto. Dice sobre el régimen de Bismarck: "En suma deseaba empero que la imbecilidad de los números y la superstición en las mayorías no se arraigara todavía en Alemania como en las razas latinas". Nietzsche rechazó todos los problemas del momento de la época de Bismarck y dice: "Hay cosas más importantes, evaluadas contra las cuales estas cuestiones son únicamente cuestiones de fachada, por ejemplo, el creciente ascenso del varón democrático y el por ello necesario embrutecimiento de Europa y el empequeñecimiento del hombre europeo". 64

Por lo tanto, Nietzsche no está en contra de Bismarck porque éste realizó la unidad alemana de una manera reaccionara, de la manera de una "revolución desde arriba" bonapartista, sino, por el contrario, porque éste era, para su gusto, demasiado democrático; porque se enrolló demasiado profundamente con la democracia; porque hizo

\footnotetext{
${ }^{63}$ Friedrich von Gentz (1764-1832), ideólogo alemán de la Restauración. Paul de Lagarde (1827-1891), filósofo de la cultura alemán, ideólogo del antisemitismo.

${ }^{64}$ Cita Lukács el fragmento póstumo 1885 / 34 / 109 y Consideraciones intempestivas.
} 
Francisco García Chicote | ¿Crítica desde la derecha o desde la izquierda? Respuesta a Ernst Bloch

concesiones demasiado grandes a la democracia. La crítica de Nietzsche a Bismarck es por lo tanto el tipo más puro de una crítica desde la derecha. 65

Esto no es ninguna casualidad. Nietzsche es celebrado por muchos intelectuales, incluso por /:varios:/ antifascistas como "espíritu libre", y de hecho condujo una lucha contra Dios, contra el cristianismo, de hecho es esta lucha una parte esencial de su obra vital. Pero se debe, también aquí, plantearse la pregunta: ¿de dónde viene el odio de Nietzsche contra Dios? ¿De dónde viene y hacia dónde va su forma de ateísmo, de anticristianismo?

Tomemos a Voltaire, ya porque de hecho Nietzsche dedicó Humano, demasiado humano a su memoria. ¿Por qué Voltaire está en contra del cristianismo? Porque este constitu/:ía:/ el soporte religioso del absolutismo feudal, porque era un obstáculo contra el progreso democrático. También Nietzsche está en contra del cristianismo, pero por motivos completamente contrapuestos. Dejemos hablar otra vez al mismo Nietzsche. Dice en El anticristo sobre el cristiano que este "es rebelde contra todo lo privilegiado a partir del instinto más bajo; jvive, combate siempre por "iguales derechos'!” Dice más adelante: "El gran número se tornó señor; triunfó el democratismo de los instintos cristianos". El cristianismo es por tanto despreciable para Nietzsche ya que es un movimiento democrático. $Y$ para que no pueda haber ningún malentendido acerca de la línea genealógica, acerca de la relación con el presente, acerca de la base político-social de su anticristianismo, Nietzsche establece la siguiente línea de los fanáticos dignos de desprecio como "tipo opuesto al espíritu que se ha vuelto fuerte y libre": Savonarola, Lutero, Rousseau, Robespierre, Saint-Simmon. Creo que es superfluo citar más. /:La antítesis se halla claramente frente a nosotros: el anticristianismo de Voltaire es un trabajo de preparación ideológica para la Revolución Francesa; Nietzsche, por el contrario, es un eslabón en la cadena de aquellos reaccionarios que quieren eliminar la herencia, el influjo de la Revolución.:/

El anticristianismo de Nietzsche es, al igual que su posición contra Bismarck, solamente un factor de su lucha central: de la lucha contra la democracia. Es un <enemigo mortal, > un claro y decidido enemigo mortal de la democracia. Desde este punto de vista critica toda la cultura moderna. Rico en espíritu, de alto nivel, en varios casos individuales oportuno, pero siempre desde este atalaya, siempre desde el lado reaccionario, siempre desde la derecha.

\footnotetext{
${ }^{65}$ El original dice: "Die Kritik Bismarcks an Nietzsche ist also..." (La crítica de Bismarck a Nietzsche es por lo tanto...). Por razones de sentido, se ha modificado en la traducción.
} 
Francisco García Chicote | ¿Crítica desde la derecha o desde la izquierda? Respuesta a Ernst Bloch

$<$ Nuestra debilidad > La inseguridad instintiva en tales cuestiones /:es:/ una típica debilidad alemana; es causada por el desarrollo no democrático de Alemania, por la falta de una vida pública en Alemania libre y agitada. Vivimos determinados fenómenos de la vida social moderna, entre ellos ante todo problemas generales de la democracia. Reconocemos su problemática, sufrimos su problemática, la criticamos. ¿Cómo podríamos hacer otra cosa, si vivimos en una época en la que la emergencia de la problemática interna de la democracia burguesa constituye un problema central del desarrollo social? Pero vivimos, sufrimos y criticamos sin siquiera pensar en el porqué o el desde dónde, en la derecha o la izquierda.66 Cuán diferente experimenta un francés educado democráticamente: Anatole France, por ejemplo, ha vivido esta problemática profundamente. Está continuamente indignado por el mero formalismo de la igualdad en la democracia burguesa. Pero cuando la critica de manera cómico-burlona o indignadopatética, siempre intercede a favor de una igualdad real, de contenido, del derecho. Critica la democracia siempre desde la izquierda.

Te pido que compares la crítica de Nietzsche sobre Bismarck con esta crítica. /:Para Anatole France, la Francia de la Tercera República no es lo suficientemente democrática::/ Para Nietzsche hay en la Alemania de Bismarck demasiada igualdad, demasiada democracia. Nietzsche de indigna de que Bismarck pacte en lo más mínimo con la democracia, de que haya disfrazado con una fachada de igualdad, con un parlamento objetivamente impotente, sobre la base del derecho electoral universal, la conservación de la hegemonía prusiana en Alemania, la conservación del poder de los Hohenzoller sobre Alemania. Demanda un dominio abierto de los "duros", de la nobleza sobre la burguesía, de los capitalistas sobre los trabajadores. Es <nuestra $>$ gran debilidad de varios antifascistas alemanes el hecho de que $<$ nosotros $>$ no noten $<$ mos $>$ u olviden $<$ mos $>$ esta tendencia decididamente reaccionaria de Nietzsche, de que no queramos darnos cuenta de que él critica todos los fenómenos esenciales de la vida social moderna desde la derecha.

$<$ ¿Es esto fascismo?> < ¿Es Nietzsche un fascista?> ¿Es la filosofía de Nietzsche fascismo? Sin duda: no. O mejor dicho: todavía no es fascismo. Sería un sinsentido antihistórico nombrar fascista a Nietzsche, ya porque en 1890 aún nadie podía tener, por motivos socio-históricos, una ideología fascista. Nietzsche es, sin embargo, el pensador más significativo de una etapa histórica del desarrollo ideológico de Alemania que ha continuado el desarrollo de la ideología reaccionaria, y de hecho en una dirección que

${ }^{66}$ Aquí asume Lukács una vacilante posición de enunciación "alemana”. 
Francisco García Chicote | ¿Crítica desde la derecha o desde la izquierda? Respuesta a Ernst Bloch

/:ayudó:/, bajo condiciones más desarrolladas y agudizadas de las luchas sociales, /:a:/ engendrar /:ó:/ la ideología fascista.

Si constatamos esta conexión histórica, no debemos de ninguna manera olvidar la enorme diferencia de nivel intelectual y moral que separa a los fascistas de Nietzsche. Pero <nuestra> la gran debilidad político-ideológica /:de los alemanes, incluso muchos antifascistas,:/ consiste precisamente en el hecho de que <nosotros $>$, fascinados por el nivel intelectual y moral de Nietzsche, olvidan qué concretamente se tuvo por objeto y se alcanzó con estas grandes fuerzas intelectuales; que <nosotros> olvidan de dónde viene Nietzsche y hacia dónde va su teoría con necesidad lógica interna.

No estoy <entonces absolutamente> desde luego en contra de una valoración justa de Nietzsche. Pero ambos lados pertenecen a la justeza histórica, la justeza histórica descansa sobre el conocimiento de la totalidad [Totalität]. Y en efecto sobre la totalidad dinámica [bewegte Ganzheit], a la que pertenece ante todo la dirección. Por mi parte, se puede por lo tanto estimar tan elevadamente a Nietzsche, disfrutarlo tan intensivamente como se quisiese; pero cuando se desatiende esta tendencia principal de su actividad, surge una confusión peligrosa.

El desarrollo no democrático de Alemania, el dominio casi sin obstáculos de la reacción ha acarreado la interesante, pero para nosotros muy adversa, situación de que en cuestiones ideológicas se dan instintos políticos muchos más seguros en la derecha que en la izquierda. Metternich apreció y disfrutó de las capacidades intelectuales y estilísticas de Börne; Gentz las de Heine. Sin embargo, ninguno de ellos se dejó por un instante influenciar en sus tomas de posición políticas, incluso si dirigían estas medidas -como por ejemplo el decreto del Bundesrat de 1835-67 inmediatamente contra los autores tan estimados por ellos. O pensá en la relación objetiva y personal entre Bismarck y Lassalle. Ambos reconocieron el nivel del otro, como hombres formados y de alta intelectualidad. Para Bismarck surgieron de este contacto conversaciones interesantes, estímulos para medidas sociales y políticas de las que pudo servirse bien para su bonapartismo reaccionario. Lassalle, por el contrario, fue arrojado a un derrotero reaccionario.

$<$ A esto se le agrega sin embargo $>$ Esta situación tiene un fundamento particular, específicamente alemán. Desde que existe la sociedad burguesa moderna, domina en Alemania, excepto por intervalos muy breves, la reacción. Está acostumbrada al dominio, a las decisiones políticas. Ha adquirido una gran práctica en el aprovechamiento y la valoración políticos de las ideologías. (Todo esto: a pesar de que la reacción alemana es,

${ }^{67}$ Se refiere a la prohibición de que se publicaran textos del grupo "Joven Alemania", del que Börne y Heine formaron parte. 
Francisco García Chicote | ¿Crítica desde la derecha o desde la izquierda? Respuesta a Ernst Bloch

a raíz de su carácter burocrático, mucho menos talentosa que las de países en los que debió luchar ininterrumpida por el poder con el progreso).

La democracia alemana fue sin embargo raramente una fuerza política -incluso como oposición-. Sus ideólogos más importantes fueron mayormente ideólogos en el sentido estrecho de la palabra, raramente se les dio poner a prueba en el plano de la praxis las consecuencias políticas de sus propias decisiones intelectuales y aprender de estas experiencias. Por ello su carácter abstracto, su ideologismo; por ello la subestimación de las direcciones en la sobrestimación del nivel intelectual, etc. como un valor en sí.

XXX68 Esta falta de oscuridad /:que surge:/, <esta> inseguridad, la confusión causada <que surge > por ella es una de las debilidades ideológicas más esenciales de todos los movimientos de izquierda en Alemania, y tampoco <nosotros $>$ los antifascistas, a pesar de muchas experiencias amargas, están de ninguna manera libres de esta debilidad.

Vuelvo a Nietzsche. En tu interesante y lindo libro Herencia de este tiempo querés rescatar en cuanto herencia de Nietzsche a lo dionisíaco. Decís: "Así fue arrojado el romanticismo al fuego; el arcaísmo, a la bestia; la filología, a una nave que zarpa ebriamente. La nave ha arribado; ahora se trata de compartir el botín, no teniendo en cuenta el 'superhombre' (este es fascismo claro como el agua), pero sí los elementos dionisíacos". 69 Cito aquí con alegría lo que decís del superhombre, si bien, como ves, yo solo lo considero en cuanto camino al fascismo, no como "fascismo claro como el agua". ¿Qué sucede sin embargo con la herencia de los “elementos dionisíacos”? Decís: “'Dionisio” es precisamente la 'moral del esclavo', un dios no desconocido, alegre, ante todo explosivo. Saturnales eran las fiestas de los antiguos esclavos, y la 'cepa Jesús', por más que la Iglesia la haya rebajado completamente, mostró en la guerra campesina más cristiana de todas menos moral esclava que lo que quieren los señores".70 Dionisio ha de ser entonces salvado como dios de un plebeyismo democrático, como patrón protector de la rebelión. En lo que concierne a la figura de Dionisio en los mitos griegos reales, estoy $<$ muy $>$ ampliamente de acuerdo con vos. ¿Pero que tiene que ver todo esto con Nietzsche, con el legado de nietzscheano? Tu concepción es especialmente inconsecuente y antinietzscheana cuando conectás las saturnales de los antiguos esclavos con la "guerra campesina más cristiana". Nietzsche habría aceptado lo último, pero justamente como consecuencia necesaria y nociva del cristianismo $\langle\mathrm{y}\rangle$; lo dionisíaco era para él precisamente el concepto opuesto, lo anticristiano, lo aristocrático.

\footnotetext{
${ }^{68}$ El manuscrito es ilegible en esta parte.

${ }^{69}$ Cf. Bloch (1962, p. 359).

${ }^{70}$ Cf. Bloch (1962, p. 362).
} 
Francisco García Chicote | ¿Crítica desde la derecha o desde la izquierda? Respuesta a Ernst Bloch

El mito dionisíaco es, de hecho, democrático en Grecia. Pero el descubrimiento moderno de este carácter suyo no tiene nada que ver con Nietzsche, <solo con > pertenece al realmente grande investigador de los mitos antiguos, <con> /:a:/ Bachofen. Este dice: “La religión dionisíaca es por ello la profesión de la democracia... Desde los antiguos, Dionisio fue celebrado como el fundador de todo tipo de libertad e igualdad universal sobre la Tierra".71 Tal vez me responderás: también Bachofen es reclamado por los fascistas como antepasado; ¿por qué deberíamos oponer en este caso resistencia y dejarles a los nazis a Nietzsche como precursor? Me parece que el motivo no es para nada tan complicado, si valoramos correctamente los caminos hacia la derecha y hacia la izquierda. Radica en el hecho de que los nazis desarrollan consecuentemente los pensamientos reaccionarios de Nietzsche -pensá en tu propio dicho acerca del superhombre-, mientras que se hallan obligados a deformar completamente a Bachofen para aprovechar para sí mismos ciertos aspectos de su actividad. Bäumler y Klages se aferran a la piedad de Bachofen respecto del mito, a su creencia en los mitos y mistifican desmedidamente esta tendencia secundaria en Bachofen. Rosenberg extirpa de Bachofen el universalismo histórico: el colosal descubrimiento de Bachofen de los dos períodos en el desarrollo de la humanidad, el del derecho materno y el del derecho paterno se torna en Rosenberg en una lucha de dos razas. En todas las "reverencias" fascistas a Bachofen se escamotea entonces precisamente su descubrimiento histórico fundamental, el descubrimiento del comunismo primitivo, lo que lo hizo precursor de la investigación progresista moderna, de Morgan y Engels. El hecho de que Bachofen, a pesar de su parcialidad romántica, sienta esta relación y establezca su conexión con Morgan al dedicarle sus "Cartas de anticuario" no molesta obviamente a los señores Bäumler, Klages y Rosenberg en lo más mínimo. Aquí se trata por lo tanto de una lisa falsificación reaccionaria, al igual que en los casos de Thomas Münzer, Hölderlin o Georg Büchner.

La situación en Nietzsche es diametralmente opuesta. Aquí continúan -mediados por Spengler y otros- los Bäumler \& Co. la línea esencial, las tendencias centrales del pensamiento de Nietzsche /:Ia lucha contra la democracia como decadencia:/.72 Por supuesto, también lo critican. Eso se sigue justamente de la situación histórica de que Nietzsche no pudo ser un fascista consecuente en los años ochenta. Pero esta es una crítica de las inconsecuencias, históricamente necesarias, de Nietzsche y naturalmente a la vez una crítica desde la derecha. Por el contrario, Friedrich Engels pudo asumir análisis esenciales de Bachofen, por ejemplo, la grandiosa explicación de la "Orestíada" y de esta manera traducir los pensamientos fundamentales del gran investigador, /:el

\footnotetext{
${ }^{71}$ Bachofen (1867, p. 151s.)

72 Alfred Bäumler, Ludwig Klages, Oswald Spengler y Alfred Rosenberg fueron pensadores pertenecientes al irracionalismo de derecha, incluso abiertamente nazi, alemán.
} 
Francisco García Chicote | ¿Crítica desde la derecha o desde la izquierda? Respuesta a Ernst Bloch

descubrimiento del comunismo primitivo:/, en la fecunda prosa del materialismo histórico y desarrollar progresivamente, mediante una importante crítica desde la izquierda, la tendencia progresista de sus ideas centrales $<$ de su pensamiento central $>$.

Independientemente de su situación favorable específicamente alemana, la reacción tiene aquí otra ventaja. Está fundada ante todo en la cuestión misma. Es más fácil falsificar la realidad que penetrar en la verdad. Todo progreso descansa en la investigación de la verdad; toda reacción, en la falsificación de las líneas fundamentales del desarrollo histórico. Es claro que en un estado de cosas tal un poco más de falsedad de la propaganda reaccionaria no puede causar ningún daño. Nada cambia en la tendencia general si la plétora de interpretaciones históricas arbitrarias, falsas se incrementa aún un poco más. La verdad y el poder de penetración del progreso presupone el correcto conocimiento de todos sus factores. La falsedad, el error son aquí un cuerpo extraño molesto. Si este se queda en la carne viviente, puede causar serias contaminaciones. Ves cuántas razones tienen los verdaderos demócratas revolucionarios <la verdadera democracia revolucionaria $>$ para la vigilancia combativa.

Justamente por esto nunca se trata de: compartir el botín. Los escritores, los eruditos nunca dejan inventarios de pensamientos muertos que podrían ser repartidos a voluntad, de los que podría ser adoptada cualquier pieza y arrojada de lado cualquier otra. Toda obra vital de un hombre significativo tiene una tendencia inmanente con una dirección determinada. Esta conforma una parte de la vida histórica de la nación. Sobrevive en ella, es desarrollada y de hecho de manera adecuada en la dirección progresista o reaccionaria que en ella reside, o es doblada, falsificada en su contrapuesto. Puesto que sin embargo se trata de la dialéctica viviente de pensamientos reales, nunca puede surgir algo verdadero progresista de un acopio de pensamientos reaccionarios.

Obviamente se trata aquí siempre sobre el núcleo, sobre la esencia. Cuanto mayor es la distancia temporal que nos separa de un pensador o un escritor, tanto más claramente puede tornarse visible este núcleo, tanto más puede desprenderse de él lo externo, lo que lo oculta. Y la lucha por la herencia, tan necesaria en lo ideológico como lo político -y tan mal conducida en general en Alemania- radica precisamente en fijar claramente este núcleo de una manifestación histórica, analizar la dirección viva, la tendencia eficaz más interior del fenómeno histórico en cuestión.

Ahora bien, aquí aparece nuevamente la pregunta central: ¿derecha o izquierda? Se debe preguntar siempre con toda firmeza: ¿esta tendencia fundamental es de derecha o de izquierda; ¿es, de acuerdo con su esencia, con su núcleo, progresista o reaccionaria? Y además: ¿es la crítica que se ejerce, mediante la que la manifestación histórica se torna en 
Francisco García Chicote | ¿Crítica desde la derecha o desde la izquierda? Respuesta a Ernst Bloch

una parte en un motor en movimiento de la vida intelectual del presente, una crítica de derecha o de izquierda? <De este modo surge para nosotros $>$ Por ello nuestra gran tarea es: excavar las tendencias que han obrado en la historia alemana para nosotros, en nuestra dirección; criticarlas desde la izquierda y de este modo desarrollarlas progresivamente; mientras que /:estamos obligados:/ a combatir con todas las armas intelectuales aquellas manifestaciones que solo pueden ser afirmadas adecuadamente desde la derecha.

Repito: la inseguridad instintiva en estas cuestiones es una de las mayores carencias de la vida cultural alemana. Desafortunadamente, es demasiado poco conocida en nuestro país la crítica democrática de los rusos de los años cuarenta y sesenta. Pues aquí alcanzó su punto culminante en todo el desarrollo cultural presocialista la sensibilidad para esta tendencia de las manifestaciones culturales. En nuestro país solo se encuentra una tal seguridad respecto de los instintos políticos y sociales de manifestaciones culturales complicadas en Lessing (y parcialmente en Heine). Por lo demás dominó en nuestro país, incluso en sinceros y agudos demócratas, una gran confusión. O bien adquiere la vigilancia democrática tendencias groseras y vulgares, político-contenidísticas. La crítica de Börne a Goethe y Hegel es un tipo característico de esto. Una tal crítica no puede ejercer ningún efecto /:verdaderamente amplio:/, fructífero y duradero a causa de la violación tendenciosa de las manifestaciones nacionales más importantes. O, lo que es aún más frecuente, se pierde la orientación de las direcciones a causa de la admiración respecto del nivel del pensamiento o de la escritura. Esto tiene como consecuencia que tonos de pensamiento reaccionarios desemboquen ininterrumpidamente en nuestro país en la ideología de escritores progresistas y causen confusiones peligrosas.

El peligro que aquí surge y la necesidad de combatirlo son muy grandes, precisamente porque las tendencias reaccionarias -y ante todo el fascismo- tienen su base económica objetiva, precisamente porque las tendencias universales a la reacción -y ante todo también al fascismo- son internacionales. Por eso crecen por todos lados de manera espontánea, por eso inundan la ideología incluso de los hombres de intención parcial o totalmente progresista... cuando no es combatida de manera ininterrumpidamente eficaz por una crítica de izquierda históricamente fundada, instintivamente segura, correcta. No se trata por lo tanto de un fatalismo fatídico, no de una fácil repartición de la herencia, del botín, sino de la dura lucha de tendencias sociales vivas que surgen forzosamente a partir de la vida social de todo pueblo.

No se puede repetir suficientemente cuán decisiva es la seguridad instintiva para la esencia correctamente percibida de las manifestaciones históricas en el desarrollo cultural de un pueblo. Pues si uno no percibe correctamente esta dirección fundamental esencial, le falta todo criterio. Precisamente aquellas escalas que aparecen en la superficie como las 
Francisco García Chicote | ¿Crítica desde la derecha o desde la izquierda? Respuesta a Ernst Bloch

más evidentes se revelan en la praxis muy frecuentemente como engañosas. Se cree por ejemplo con frecuencia que el enemigo común supone a la vez una dirección interna común. Esto es muy frecuentemente un serio error.

Pensá nuevamente en la relación Bismarck-Lassalle. Bismarck debió luchar con la democracia alemana, con la burguesía liberal para imponer su forma de solución de la unidad alemana. Al mismo tiempo tuvo lugar en Alemania el proceso de separación de la democracia proletaria de la burguesa, la liberación por parte de las organizaciones proletarias que apenas se formaban tanto externa como internamente respecto del influjo conductor de la burguesía liberal. Si por lo tanto en este tiempo apareció Lassalle con una aguda crítica de la debilidad de la resistencia de la burguesía liberal contra Bismarck, esto era /:en sí:/ correcto; si extendió esta crítica política sobre manifestaciones culturales, literarias y filosóficas, esto era en sí igualmente correcto. Fatal fue solamente que haya concebido a la burguesía liberal como enemigo común con Bismarck. Pues este combatió a la burguesía liberal desde la derecha, mientras que el movimiento proletariado creciente y los pequeños dispersos restos de la democracia del 48 la combatieron desde la izquierda. Mediante esta concepción fundamentalmente falsa de las direcciones esenciales de la vida política y cultural de Alemania en los años sesenta Lassalle no contribuyó a clarificar y desarrollar la democracia alemana (ni la burguesa, ni la proletaria), sino que por el contrario dejó en la estacada al por entonces débil o ambiguo, vacilante movimiento democrático hacia una solución progresista de la unidad alemana, contribuyó a la victoria del bonapartismo bismarckiano.

Naturalmente, esta relación no es tan simple incluso desde el lado de Lassalle. Intentó mantener las diferencias de principio, la posibilidad de separarse. Pero en el osado juego de comer cerezas con el diablo, ${ }^{73}$ sufrió en la práctica una derrota total. $Y<$ también aquí> es muy provechoso recordar que también aquí el famoso problema del "nivel"... jugó un papel muy grande; Lassalle destaca por ejemplo en sus conocidos discursos renanos, en los que fueron proclamadas las consecuencias de la alianza, que Bismarck, si bien un enemigo, también es un hombre verdadero, a diferencia de los representantes liberales, que son viejas solteronas. /:Más allá de lo que uno pueda traer a colación para excusar a Lassalle,:/ <Sin embargo> aquí aparece /:empero:/ una confusión importante, sintomática y fatal para el desarrollo alemán: una caída en la reacción a partir de una crítica apasionadamente impaciente del capitalismo. Lassalle no entendió el problema central de su tiempo, la cuestión de si la unidad alemana había de emerger de un modo democrático o antidemocrático. Por ello, en vez de criticar a la burguesía liberal desde la izquierda, y

\footnotetext{
${ }^{73}$ Se trata de una expresión coloquial, con cierta presencia en la literatura fáustica, que advierte sobre el peligro que representa intentar acordar bona fide con las autoridades. Aparece en la compilación de fábulas tardomedieval de Ulrich Boner: "no es bueno comer cerezas con el señor / [...] / quien quiera comer cerezas con él / este le tira los carozos / en los ojos...”.
} 
Francisco García Chicote | ¿Crítica desde la derecha o desde la izquierda? Respuesta a Ernst Bloch

de esa manera clarificar a la democracia burguesa alemana, desarrollarla, educar al emergente partido de los trabajadores para la lucha por una democracia revolucionaria, se adhirió a la crítica de derecha de la burguesía liberal y con ello causó un daño difícil de subsanar al desarrollo democrático de Alemania.

Pues se trata aquí de mucho más que un error táctico único. Desde la teoría del estado lassalleana, que en su aplicación, el hecho de que el primer paso al socialismo tiene que suceder a través del estado prusiano de Bismarck, de la cual provino la teoría del "crecimiento superador" de este Estado prusiano hacia el socialismo, hasta el rol revolucionario de Federico II en Prusia, penetraron en la historia alemana un montón de pensamientos reaccionarios en el movimiento obrero alemán. E incluso si un hombre de la sensibilidad democrática genuina de Mehring quedó fascinado por el "nivel" de Lassalle en estas cuestiones y no estuvo en condición de criticar correctamente desde la izquierda los malos caminos aquí tomados hacia el campamento de la reacción, no debe maravillar que aún hoy sobrevivan en el movimiento obrero muchas concepciones dañinas y reaccionarias de este tipo.

Estos son solo algunos ejemplos de la historia y la historia intelectual alemanas. Desafortunadamente pueden acrecer muy fácilmente, pues casi todo paso de nuestro desarrollo político e intelectual muestra los síntomas de esta inseguridad de instinto de la izquierda alemana. Aquí se trata entre nosotros no de una completitud histórica, sino de una clarificación de las consecuencias, y esto se $<$ te $>$ ha vuelto claro a partir de estos pocos ejemplos, como espero.

Hablás de la caída de Hitler. Con razón, pues es tarde o temprano inevitable. ¿Después qué? En mi opinión, después debe implementarse <comenzar> más que nunca la lucha contra toda ideología reaccionaria. Precisamente porque tenés razón en la cuestión de la base económica, del carácter internacional de las tendencias reaccionarias, del fascismo, el período después de la caída de Hitler -ifinalmente!- debe ser incluso en Alemania un período de la lucha clara y decidida contra toda ideología reaccionaria. Creo que ya no es necesario adentrarse detalladamente en las razones. < Es claro que $>$ Esto debe suceder, para que no puedan fortalecerse nuevos usufructuarios de la problemática económica de nuestra época, de la solidaridad internacional de las corrientes reaccionarias. Para que -ifinalmente!- surja un movimiento realmente democrático, una ideología realmente democrática, consciente de sus metas, sólida, procedente de la vida alemana, de las existentes pero enterradas tradiciones de la historia alemana, que rompa radicalmente con todas las formas de manifestación de la miseria alemana. 
Francisco García Chicote | ¿Crítica desde la derecha o desde la izquierda? Respuesta a Ernst Bloch

Por lo tanto, no es de ninguna manera un deporte filosófico buscar los precursores del fascismo, sino una necesidad ideológico-política actual y abrasadora. Suena muy radical cuando decís "El nazi se cocina en su propia salsa". $<$ En realidad $>$ En la práctica les das, excepto a Hitler y Rosenberg, a todos los reaccionarios alemanes de antemano una amnistía intelectual y un campo de acción político, ideológico. Pues es claro que después de la caída de Hitler, todos se apurarán por arrojar "Mi lucha" y "Mitos del siglo XX" al estercolero. Eso es tan justo como correcto y beneficioso. ¿Pero qué se alcanza así, si todas las fuentes brotan tranquilas, a partir de las cuales luego de un cierto tiempo un nuevo tunante, un nuevo veneno para el pueblo alemán pueda fermentar? Por cierto solamente si a través de la vigilancia ideológica democrática no nos echamos al hombro tales intentos.

Sé que en esta meta estamos completamente de acuerdo. /:Solo es una:/ lástima que nuestro dialogo sobre las discrepancias en el método tuvo que convertirse, /:de acuerdo con la forma:/, en un monólogo paralelo. Tal vez sea sin embargo posible que estas líneas mías ayuden a hacerlo un diálogo fluido.

En vieja amistad, tu

\section{Georg Lukács}

\section{Referencias}

BACHOFEN, Johann. Die Unsterblichkeits/ehre [La doctrina de la inmortalidad]. Berlin: Keiper, 1867.

BLOCH. Ernst. "Der Nazi kocht im eigenen Saft". En: MESTERHÁZI, Miklós y György MEZEI (eds). Ernst Bloch und Georg Lukács. Dokumente zum 100. Geburtstag [Ernst Bloch y Georg Lukács. Documentos para el centenario de sus nacimientos]. Budapest: MTA Filozófiai Intézet, Lukács Archívum, 1984, 274-277.

BLOCH. Ernst. Erbschaft dieser Zeit. Frankfurt a.M.: Suhrkamp, 1962 
Francisco García Chicote | ¿Crítica desde la derecha o desde la izquierda? Respuesta a Ernst Bloch

MESTERHÁZI, Miklós y György MEZEl (eds). Ernst Bloch und Georg Lukács. Dokumente zum 100. Geburtstag [Ernst Bloch y Georg Lukács. Documentos para el centenario de sus nacimientos]. Budapest: MTA Filozófiai Intézet, Lukács Archívum, 1984.

MESTERHÁZI, Miklós. "Vorwort" [Prólogo]. En: MESTERHÁZI, Miklós y György MEZEl (eds). Ernst Bloch und Georg Lukács. Dokumente zum 100. Geburtstag [Ernst Bloch y Georg Lukács. Documentos para el centenario de sus nacimientos]. Budapest: MTA Filozófiai Intézet, Lukács Archívum, 1984, I-L.

ZUDEICK, Peter. 1992. Ernst Bloch. Vida y obra. Valencia: Alfons el magnánim. 